\title{
Dalcídio Jurandir e o romance de 30 ou um autor de 30 publicado em 40
}

\author{
Marlí Tereza Furtado
}

RESUMO: O texto visa a discutir o alinhamento do romancista marajoara Dalcídio Jurandir junto a autores consagrados pelo cânone como representantes do romance da década de 30, na literatura brasileira. Considera-se, sobretudo, o caráter intimista de suas obras iniciais, principalmente Chove nos campos de Cachoeira e Marajó, escritas em 30, mas publicadas em 40, para demonstrar que ao autor não cabe apenas no enquadramento de autor regionalista.

PALAVRAS-CHAVE: Dalcídio Jurandir; romance de 30; Chove nos campos de Cachoeira; Marajó

\begin{abstract}
The text aims to discuss the alignment of the marajoara Dalcídio Jurandir, novelist, along the Canon established by the authors as representatives of the romance of the 30s in Brazilian literature. It is considered, in particular, the intimate character of his early works, mainly in Chove nos campos de Cachoeira and Marajó, written in 30, but published in 40, to demonstrate that the author does not fit just the framing of regionalist author.
\end{abstract}

KEYWORDS: Dalcídio Jurandir; romance of the 30; Chove nos campos de Cachoeira; Marajó 
O escritor marajoara Dalcídio Jurandir (1909-1979) viveu a década de 1930 entre Belém e outras cidades do baixo Amazonas (Gurupá, por exemplo), conforme prestava serviços de funcionário público. Nessa década, colaborou, principalmente, com a imprensa local, escrevendo para diferentes periódicos e nos deixou cerca de quarenta textos, ${ }^{1}$ distribuídos entre o jornal O Estado do Pará e as revistas Escola, A Semana, Novidade e Terra Imatura. Nesse quadro, temos ensaios, críticas literárias, poemas, reportagem e crônicas, o que revela tanto o exercício do autor como literato quanto como jornalista, dividido, nessa atividade, entre o ensaio e a crítica literária.

No exercício da escrita literária, ao lado dos poemas e crônicas, inicia seu trabalho ficcional escrevendo dois romances. O primeiro deles, Chove nos campos de Cachoeira, escrito em 1929, reelaborado em 1939, foi enviado, em 1940, ao concurso da editora Vecchi e do jornal Dom Casmurro, do qual saiu vencedor. Ironicamente, esse romance concorreu com Marinatambalo, o outro livro "passado a limpo" por Dalcídio Jurandir no mesmo ano de 1939 e enviado ao concurso por dois de seus amigos, que lhe avisaram quando ele já tinha despachado aquele para o certame no Rio. ${ }^{2}$

O livro premiado veio à publicação no ano seguinte ao concurso, em 1941, ano em que o autor se mudou para o Rio de Janeiro e passou a colaborar com a imprensa carioca. O romance não premiado foi publicado somente em 1947, com o título modificado para Marajó. Assim entrou Dalcídio Jurandir para o cenário literário brasileiro e prosseguiu sua trajetória, publicando mais nove romances, um deles sob a custódia do Partido Comunista Brasileiro (РСВ), ao qual se filiou nos anos de 1940, para seguir as normas do realismo socialista. Linha do parque (1959), um romance proletário, centrado no sul do país, embora censurado pelo próprio partido, ${ }^{3}$ destoa dos outros dez que enformam o ciclo do Extremo Norte e têm, todos eles, seus enredos centrados na Amazônia paraense.

1. Em pesquisas realizadas entre 2009 e 2013, nos projetos Dalcídio Jurandir e o realismo socialista e Dalcídio Jurandir: o jornalista e o romancista, coletamos 39 textos de Dalcídio Jurandir para a imprensa paraense e cerca de trezentos textos para a imprensa do Rio de Janeiro.

2. É curioso que, dentre os cinquenta e dois livros inscritos, Marinatambalo ficou entre os quatro últimos que foram para a definição do prêmio, mas foram premiados apenas dois: Chove nos campos de Cachoeira, de Dalcídio Jurandir, e Ciranda, de Clóvis Ramalhete, não havendo um terceiro lugar como alguns se apressam em afirmar.

3. Ver MORAES, Dênis de. O imaginário vigiado. A imprensa comunista e o realismo socialista no Brasil (1947-53). Rio de Janeiro: José Olympio, 1994. 
Aos dois primeiros títulos, escritos na década de 1930, mas publicados na de 1940, somam-se, formando o ciclo acima referido, os seguintes romances: Três casas e um rio (1958), Belém do Grão-Pará (1960), Passagem dos inocentes (1963), Primeira manhã (1967), Ponte do Galo (1971), Os habitantes (1976), Chão dos lobos (1976), Ribanceira (1978).

O ciclo do Extremo Norte demonstra que o autor seguiu um projeto estético por quase quarenta anos, embora se desgastasse muito com o processo de publicação de seus livros, sempre demorado, fazendo que as obras "adormecessem" na gaveta por longos períodos. Pensemos nos oito anos de Marajó, que teve tempo de passar de Marinatambalo 4 para um segundo nome, Missunga, e depois para Marajó; e Linha do parque, pronto no início da década de 1950, mas publicado ao final dela.

Nesse trajeto literário, Dalcídio Jurandir não se deslocou, tematicamente, da década de 1920 de nossa história, seguindo os passos da personagem Alfredo, um menino mestiço, de pai branco e culto e de mãe negra, quase analfabeta, entre os dez e os vinte anos, e focaliza a Amazônia da década de 1920, com retrospectivas à época áurea da borracha, encerrando o último romance da série com alusões à revolução de outubro de 1930.

A trajetória de Dalcídio Jurandir em nossa literatura é, no mínimo, curiosa: iniciada em 1930, sob a ditadura de Vargas, e concluída em 70, sob a ditadura militar pósgolpe de 1964; apesar de laureada com quatro prêmios, ${ }^{5}$ amargou um quase ostracismo na crítica acadêmica e nas histórias literárias brasileiras. Quando de seu surgimento, seu nome é alinhado entre os autores menores e continuadores de nossa produção romanesca de 30; já na década de 1970, na qual publicou cinco romances, passou ao largo dos autores considerados renovadores e representativos, como Ignácio de Loyola Brandão, Ivan Ângelo, Antônio Torres.

Em ambos os períodos, entretanto, o que caracteriza a obra dalcidiana é seu caráter inovador. $\mathrm{O}$ autor intensifica o trabalho com as técnicas narrativas de romance em romance, no sentido de produzir uma obra em que o esfacelamento é traço de composição, como podemos verificar em Ribanceira, a última do ciclo.

O caráter inovador de seu primeiro livro, o premiado Chove nos campos de

\footnotetext{
4. Este teria sido o primeiro nome da ilha de Marajó.

5. Além do prêmio de 1940, recebeu por Belém do Grão-Pará, em 1960, o Paula Brito, da Biblioteca do estado da Guanabara e o Luísa Cláudio de Souza, do Pen Club do Brasil; em 1972, recebeu o prêmio Machado de Assis, da Academia Brasileira de Letras, pelo conjunto de sua obra.
} 
Cachoeira, é que oblitera o enquadramento adequado, tanto da obra quanto de seu criador, na década em que foi elaborada, muito embora tenhamos de considerar o peso de ter sido publicada dois anos depois de sua elaboração. Um aspecto comum na crítica sobre Dalcídio Jurandir é a sua colocação como representante do regionalismo, ora do "grupo do norte", ${ }^{\circ}$ ora do "amazônico", ora do paraense e até representante de "um regionalismo menor". ${ }^{8}$ No entanto, a crítica de seu conterrâneo Benedito Nunes o distancia "consideravelmente das experiências regionalistas" porque, segundo ele, os romances de Dalcídio Jurandir

[...] são ficções que apresentam uma interiorização muito grande, cada vez mais densa; são, na verdade, as aventuras de uma experiência interior. Chego a pensar que o conjunto desses romances forma uma espécie de À La Recherche... escrita na Amazônia e que Dalcídio é, um pouco, o nosso Proust. ${ }^{9}$

Percebemos que Benedito Nunes, embora já em momento mais avançado em relação aos dos outros críticos, tenta chamar a atenção para os aspectos genuínos da obra dalcidiana, sem cair nas classificações rápidas e generalizantes em que, parece, caíram alguns historiadores de nossa literatura e alguns dos críticos que escreveram em seguida ao lançamento do livro de estreia do autor, o que foi incentivado pelo jornal Dom Casmurro ao oferecer um prêmio para as melhores críticas aos dois romances premiados no certame de 1940. E o caráter genuíno da obra a que nos referimos é o seu traço intimista, traduzido por Nunes como "uma interiorização muito grande" e como "as aventuras de uma experiência interior".

Ao refletir sobre o dilema entre historicismo e esteticismo que demarca nossa história literária, Luís Bueno ${ }^{10}$ afirma que

No decorrer do século XX, os regimes políticos fechados de direita levaram a uma reação por parte da intelectualidade de esquerda, muitas vezes hegemônica, cuja

6. Coutinho, Afrânio. 1987.

7. MoIsés, Massaud. O modernismo. São Paulo: Cultrix, 1989, p. 251.

8. Bosi, Alfredo. História concisa da literatura brasileira. São Paulo: Cultrix, 1978, p. 478.

9. Entrevista a José Castello para o Jornal de Poesia, s.d. (grifo nosso).

10. Bueno, Luís. Uma história do romance de 3o. São Paulo: Edusp; Campinas: Ed. da Unicamp, 2006, p. 17. 
tendência foi a de sobrevalorizar a literatura empenhada. Um efeito claro desse fenômeno, relativo aos anos 30 , é o apagamento a que foram condenados os autores ditos intimistas que surgiram naquele momento.

A verificação do apagamento das obras intimistas, uma distorção para Bueno, e por ele creditado a uma crítica empenhada e não a uma literatura empenhada, nos ajuda a redimensionar a dificuldade de estudiosos que se propuseram a trabalhar com o romance de 30 e a constatar que o "regionalismo" muitas vezes salvou alguns autores e respectivas obras do total esquecimento. Talvez seja o caso de Dalcídio Jurandir em seu surgimento. Ao ser considerado regionalista, não foi esquecido, mas o tom intimista de sua obra, se não obscurecia a visão dos pobres e da pobreza da vila de Cachoeira e, por extensão, da ilha de Marajó, reforçava a urdidura romanesca que não permitia ao leitor enlevar-se de modo deslizante a seguir um enredo facilitado pela lei da causalidade e da temporalidade cronológica.

Assim, temos em Chove nos campos de Cachoeira um desfilar de pobres e desvalidos, coadjuvantes de dois protagonistas, o herói decadente Eutanázio e seu meio-irmão, Alfredo, sendo aquele adulto, filho do primeiro casamento de major Alberto, o secretário da intendência local, branco e de formação erudita, enquanto este, criança ainda, é fruto do casamento informal, visto negativamente na época, de major Alberto com dona Amélia, negra e quase analfabeta.

Eutanázio vem marcado pelos signos da náusea, do nojo, da angústia e da solidão. Perto dos quarenta anos, mal cuidado e doente, é a decrepitude em pessoa: encostado na casa do pai, não tem dinheiro, nem emprego, mas, profundamente apaixonado por Irene, não se abstém do papel de provedor de desejos materiais que lhe conferem as mulheres da casa de seu Cristóvão, o chalé em que mora Irene. Cumpre ele um ritual diário de humilhação, num vaivém entre o chalé do pai e o de seu Cristóvão e, instigantemente, como um flâneur, percorre as ruas de uma Cachoeira pobre, decaída, sem perspectivas.

Embora dado a poeta, além de escrevinhador de cartas dos apaixonados analfabetos de Cachoeira, Eutanázio cumpre uma saga obsessiva de amor por Irene, narrada em vinte capítulos, por meio de uma voz em terceira pessoa, que faz uso abundante do discurso indireto livre e do monólogo interior. De vocação um tanto violenta, paralisa-se diante de Irene, a representação da musa perversa, que o esconjura e lhe oferece o riso escarnecedor em recompensa pelo amor e dedicação que ele lhe oferece. Nessa situação, ele responde, sempre em constantes elucubrações, com ódio e asco ao mundo, 
junto ao autodesprezo e autoaniquilamento, a ponto de se deixar morrer, sem tratar a doença que o consome, cumprindo um dos sentidos de seu nome: eutanásia. Esses dados bastam para caracterizá-lo como um herói fracassado, constante na literatura da década.

Ao seu lado, Alfredo inicia o percurso que o levará, senão à decadência física do irmão, à mesma impotência que o fazia divagar em flâneries noturnas por Cachoeira. Alfredo completará um trajeto de identidade racial, cultural e social no decorrer do ciclo. No primeiro livro, entretanto, já elucubra sobre esses elementos, tentando entender "a ordem do mundo".

Voltando ao crítico, Benedito Nunes, é interessante como ele percebeu primeiro a recriação de uma dimensão universal (uma espécie de À La Recherche) no particular, a Amazônia, invertendo a posição do foco daqueles que intentam defender determinado autor ou obra da pecha do regionalismo ${ }^{11}$ através da inserção do particular no universal, depois de destituírem esse particular do tão batido quanto temido "pitoresco". Vale dizer que virou clichê de certa crítica concluir que se determinada obra é regional, mas não pitoresca, será universal.

A dimensão regional está presente nos romances dalcidianos, às vezes em tom mais forte, às vezes mais esmaecido, sem, no entanto, "qualquer caráter de tendência impositiva, ou de requisito de uma equivocada consciência nacional". ${ }^{12}$ Para se entender isso é necessário reportar-se às palavras do próprio Dalcídio a respeito de sua obra e da literatura brasileira. Tomemos algumas falas do autor:

Foi a tentativa inicial de transmitir, em termos de ficção, o que vive, sente e sonha o homem marajoara. Vale como um depoimento, uma memória, uma denúncia, uma antecipação. Tentei captar o trivial, o não heroico, o dia a dia da vida marajoara, vida que parece tão coisa nenhuma e é, no entanto, tão de todo mundo. Não figurei Marajó como um inferno nem tampouco como um paraíso perdido. Criei nela o meu universo, a terra encantada, e escrevi com prazer, candura e desencanto, com obstinação ingênua e

11. Parece que, a partir do estudo de Lúcia Miguel Pereira, em Prosa de ficção - de 1870 a 1920, em 1950 se associou regionalismo a pitoresco, e ambos os termos ganharam tom depreciativo, razão de muitos autores terem rejeitado tal denominação.

12. CANDido, Antonio. "Literatura e subdesenvolvimento". In: A educação pela noite e outros ensaios. São Paulo: Ática, 1987. 
saboroso desgosto, horas e horas vivi na mais divertida e amarga ilusão literária. A flauta é tosca, toquei de orelha mas toquei com sentimento. ${ }^{13}$

Eu não sou um escritor de grande público. Os meus livros não têm o principal encanto das grandes tiragens, que é habilidade para fazer o leitor ser atraído pelo enredo, pelo desenvolvimento da urdidura. Eu me fixo muito na linguagem, nos vagares da narrativa, no ritmo lento das cenas. ${ }^{14}$

A nossa literatura está em ascensão. E fará parte da universal à medida que se tornar mais brasileira, mais rica de nosso povo. ${ }^{15}$

Observem-se nos excertos: a postura de Dalcídio como cantor do universo marajoara, recriado por ele; a consciência do autor de uma tradição literária oscilante entre retratar a Amazônia como paraíso ou como inferno; a opção pela técnica que retira sua obra do que ele mesmo chamou de "narrativas simples"; a preocupação com o destaque de nossa literatura no panorama mundial sem perder de vista o caráter nacional dessa literatura.

Essas declarações indicam, ainda, àqueles que querem tão somente retratar Dalcídio Jurandir como regionalista, que a técnica utilizada por ele quebra em sua obra o tom naturalista a que se associa muito do que foi produzido no Brasil dentro dessa linha. O jogo com o tempo, a mistura de vozes, os monólogos interiores, tudo o que ajuda no traço da simultaneidade presente em suas narrativas as distancia do naturalismo.

Na criação de um mundo derruído, por onde trafegam heróis corroídos, Dalcídio filia-se à linha dos autores recriadores de universos decadentes, como os do Nordeste, especificamente José Lins do Rego e os companheiros de partido Graciliano Ramos e Jorge Amado. Logo, muito do que se falou para realçar sobretudo a obra dos dois primeiros autores vale para alinhar Dalcídio a eles.

13. Entrevista "Um escritor no purgatório", concedida a Antonio Torres, Haroldo Maranhão e Pedro Galvão. Revista Mensal de literatura ESCRITA, ano 1, n. 6, 1976.

14. Id., p. 4.

15. “Dalcídio fala dos outros e de si”. Entrevista a Bastos Morbach. Asas da Palavra. Belém, Unama, n. 4, jun. 1996. 
Assim, comecemos por Flora Süssekind,$^{16}$ que, apontando a analogia entre literatura e ciências sociais na ficção naturalista de 30 , indica a presença do ciclo como modelo romanesco básico na década, porque "ciclo" era palavra-chave nas interpretações econômicas do país. No ciclo, narravam-se transformações que não se deram do dia para a noite, que tiveram larga duração, daí os vários volumes para sua representação ficcional.

A autora diz que José Lins do Rego e Jorge Amado escreveram todo um ciclo para "matar senhores de engenho e coronéis"; logo, no Ciclo da cana-de-açúcar e no Ciclo do cacau foram necessários muitos volumes para se narrar a decadência das grandes famílias patriarcais nordestinas e do seu modo de explorar as terras, para descrever a passagem de um engenho a usina e o aparecimento do grande proprietário burguês. ${ }^{17}$

Nesse contexto, Flora Süssekind destaca a originalidade de Graciliano Ramos, que criou a série em lugar do ciclo, fraturando a verbosidade do naturalismo de então e funcionando como "faca amolada no modelo romanesco dominante", principalmente porque, ao explicitar em seus romances o trabalho com a linguagem, "Graciliano joga por terra a obsessão fotográfica e documental dominante no neonaturalismo de 30, dominante tanto num Jorge Amado quanto num José Lins do Rego". ${ }^{8}$

A autora também observa o modo como o Paulo Honório de São Bernardo se refere à terra, "como algo que 'via de relance', diferente dos personagens presos à cana e ao cacau de Jorge Amado e José Lins e das descrições de canaviais, bagaceiras, terras do cacau, tão frequentes na novelística dos anos 30 " ${ }^{19}$.

A partir desses apontamentos, pensemos em Dalcídio Jurandir, inserto em 30 ao iniciar o ciclo Extremo Norte e ao produzir seus dois primeiros romances: Chove nos campos de Cachoeira e Marajó. Observemos, primeiramente, que o autor se utiliza do ciclo romanesco não para narrar o processo em andamento da queda do ciclo da borracha, nem a passagem de um modo de apropriação da terra a outro, ou de um modelo econômico a outro. Ele desvela o vazio de um modelo econômico; no vazio deixado pela queda de um ciclo econômico trafegam suas personagens, e do

16. Tal Brasil, qual romance? Uma ideologia estética e sua história: o naturalismo. Rio de Janeiro: Achiamé, 1984.

17. Id., p.17o.

18. Ibid.

19. Id., p. 171. 
memorialismo de algumas recuperamos o auge desse ciclo já extinto; nas ruínas desse tempo um de seus protagonistas (Eutanázio) termina um trajeto de tensão entre ego e mundo, e outro (Alfredo) inicia, para depois amadurecer, sem completar, um transcurso de aquisição de consciência social e de identificação com as camadas populares desse universo depauperado.

Há, pois, no ciclo romanesco de Dalcídio Jurandir, e já nos dois primeiros romances, um trabalho refinado de articulação temporal. O presente da narração, figurado no pretérito perfeito, se amplia à medida que se revela um passado mais distante, correspondente ao imperfeito e mais-que-perfeito, em todo caso, já acabado. Um dos estudos de Pedro Maligo ${ }^{20}$ sobre Extremo Norte recai sobre o tempo e nos ajuda a compreender esse aspecto. Segundo ele:

Um dos principais eixos que orientam a representação da Amazônia em Jurandir é o tempo. Se, para fins de análise, divide-se tal eixo em tempo material e tempo idealizado, subdividindo-se cada qual em passado e presente, nota-se que tais unidades mantêm uma relação assimétrica, de vez que o elemento correspondente ao passado idealizado recebe pouca atenção. Uma vez que o assunto principal de Jurandir é a vida entre as camadas sociais mais pobres, o tempo material presente é o tempo da narração dos eventos ou descrição de estados associados com uma realidade econômica difícil. ${ }^{21}$

Ele ainda diz que Dalcídio Jurandir explora continuamente a dualidade implícita do passado como realidade defunta (para sempre apagada) e memória eterna (de nunca se apagar), sendo a última não definida apenas como nostalgia, mas aparecendo como impotência que uma personagem sente ao tentar compreender as devastadoras consequências dos acontecimentos históricos. "Isto leva a estados de introspecção, ou a um sentimento de determinismo que se manifesta como apatia ou desespero diante da realidade que evoluiu da decadência econômica."22

Complementando, Maligo ainda observa "um sentimento de desconforto existencial que atravessa a vida de personagens para as quais o passado representa um

20. Maligo, Pedro. "Ruínas idílicas: a realidade amazônica de Dalcídio Jurandir". Revista USP, n. 13, 1992.

21. Id., p. 50.

22. Id., pp. 50-1. 
fechamento, algo que não pode ser recuperado nem como escape do presente, nem como solução econômica possível”. ${ }^{23}$

Acrescentamos às afirmações de Maligo que, diante do sentimento de impotência a que se sentem aprisionadas, as personagens do presente das narrativas dalcidianas, principalmente as populares, compensam essa inércia apontando para um movimento anterior ao ciclo da borracha e retido na memória eterna, a Cabanagem. Desse modo, se, conforme ainda Maligo, na interpretação da História Dalcídio demonstra que "a grandiosidade do Ciclo da Borracha esvaiu-se, restando apenas a possibilidade de crítica e o fracasso inevitável das tentativas de reconstrução", ${ }^{24}$ por outro lado, a Cabanagem, apontada em quase todo o ciclo romanesco, ressoa como um tempo mítico na voz popular e suplanta o fechamento desse passado ligado ao econômico porque, como tempo mítico, acena para a possibilidade do retorno, presentificando pelo menos as possibilidades de resistência às opressões à qual a Cabanagem está ligada.

Voltando os olhos para os dois romances iniciais citados, lembremos que Marajó se faz a única narrativa de Extremo Norte em que Dalcídio retrata de perto a apropriação da terra. No contexto interno da obra, entretanto, ainda vige o sistema de herança do grande latifúndio e tudo indica a permanência da mesma estrutura, a menos que se queira ver nas visões grandiosas de projetos desenvolvimentistas de Missunga, um dos protagonistas e último Coutinho a herdar as terras, a possibilidade da mudança para a apropriação propriamente burguesa da terra, apontada por Flora Süssekind. ${ }^{25}$

Se o modelo agrário persiste e o texto retrata a continuidade desse processo, não deixa, entretanto, de indiciar o aceleramento da industrialização na zona urbana e o movimento que está causando nos interiores, abrindo perspectivas diferentes, inclusive e principalmente, para a mulher que não pode atender mais aquele modelo patriarcal. Daí o trabalho do autor em duas personagens femininas também protagonistas da obra: Orminda e Alaíde, a primeira retratada como uma mulher livre, pelo menos sexualmente, e a segunda a apontar para o trabalho assalariado na fábrica em Belém.

\footnotetext{
23. Id., p. 51.

24. Ibid.

25. Audemaro Taranto Goulart aponta essa possibilidade de mudança na leitura que faz da obra, à luz do texto de Freud Totem e tabu. Cf.: "Marajó sob o signo da antropologia e da estética". Asas da Palavra, Belém, Unama, vol. 8, n. 17, 2004.
} 
Marajó, entre os dez romances, é um dos que parecem mais fortemente carregados de cor local. Uma das razões a explicar essa sensação é o seu papel sui generis dentro do ciclo, parecendo retirado dele, mas também focalizando em zoom o problema agrário da região. Salta dele a impressão de um universo mais fechado e parece que o leitor vê mais de perto a pintura dos rios, lagos, alagados, pastos, arrebóis, fauna, flora e costumes locais.

Ressalve-se que a obra consegue driblar o peso naturalista do período, sobretudo porque o que seria documento etnográfico incorpora-se como elemento de tessitura da narrativa: "o romance de Dona Silvana" e outras histórias populares, como a da Maria de Pau, que reforça o conteúdo da primeira. A forma fechada do "rimance" modela a personagem de Orminda, cuja representatividade de princesa presa na torre funciona como paradigma da prisão dos seres humanos naquele universo em que fica mais patente a reificação humana. Na diferença de registro, corta-se o tom documentário em que o texto poderia cair.

A linguagem, belissimamente trabalhada no romance, ajuda-o a se distanciar do vezo naturalista de 30. Audemaro Taranto Goulart aponta a manifestação estética no nível da linguagem da obra, chamando a atenção para "a delicadeza da composição linguística, a graciosidade com que o autor constrói cenas e situações", para "a ternura com que fala de assuntos que poderiam ser significativamente apelativos" ${ }^{26} \mathrm{O}$ estudioso cita como exemplo uma passagem cujo lirismo não escapa ao leitor:

Apearam-se diante do lago e dos campos que a luz descobria. Viram os garrotes erguerem e acariciarem as belas novilhas. Não se ouviam mais as vozes dos pescadores na lanceação. As virgens novilhas estavam amorosas e belas e o dia parecia nascer do fundo do lago. Os garrotes, babando, escuros e lentos avançaram e cobriam as novilhas espantadas. No dia subindo, um voo de garça tentava purificar a paisagem ${ }^{27}$.

Vale a reprodução do que o crítico comenta sobre o excerto citado:

Note-se como o narrador desvia o rito amoroso entre o homem e a mulher para a paisagem circundante. Lá estão os significantes metafóricos da conjunção amorosa - garrotes

26. Id., p. 10.

27. Jurandir, Dalcídio. Marajó. Rio de Janeiro: Ed. Cátedra, 1978, p. 239. 
e belas novilhas - que se entregam num cenário bucólico, recortado na imagem auditiva do silêncio dos pescadores e nessa outra, visual e cósmica, em que o dia parece vir do fundo do lago. O cenário é puro, no sentido de que o leitor está diante de uma paisagem natural mas, ainda assim, uma garça vem emoldurar o quadro, pois tentava purificar a paisagem. É essa palavra mesmo - tentava - que dá a dimensão do projeto estético de Dalcídio, uma vez que ela indica, de modo nítido, que o autor desconfia da depuração a que submeteu a narrativa, como que preocupado em elidir nela tudo quanto fosse afirmação direta e apelativa da tópica da sexualidade..$^{28}$

Na linguagem de Marajó, tal como fez em menor proporção em Chove nos campos de Cachoeira, o narrador exercita o máximo possível a fusão da linguagem poética com a referencial. À medida que é bem-sucedido, ele acaba filtrando os elementos de cor local, pois se utiliza da animização da natureza não apenas para "as paradas descritivas" de que nos fala Ligia Chiappini, ${ }^{29}$ aliás, raríssimas na obra, mas para revelar o homem ligado a essa natureza. Observe-se como o homem está sempre presente nos quadros da natureza:

Ramiro ferrou o animal com garbo [...]. No urro do animal ferrado, a tarde morria..$^{30}$ Missunga [...] Atravessou um balcedo, bandos de patos selvagens passavam. Puxou a espingarda da cilha e atirou. Os patos subiram e outros bandos passaram rápidos num voo mais alto. Missunga voltou a atirar para o céu até o último tiro e a noite tombou vagarosa, sangrando ainda do crepúsculo, como uma garça ferida. ${ }^{31}$

Missunga saiu no rumo do porto. Ciloca ameaçava Felicidade. O grunhido do porco que Tenório matava. Crianças choravam e as mães as espancavam. O sol tinia, dava liamba às árvores que amoleciam, estáticas, sonhando, num torpor. ${ }^{32}$

[...] Os pensamentos vêm e vão como aqueles galhos do pequiazeiro no vento. ${ }^{33}$

28. Goulart, Audemaro Taranto. Op. cit., p. 11.

29. Leite, Ligia Chiappini de Moraes. Regionalismo e modernismo. São Paulo: Ática, 1978.

30. Jurandir, Dalcídio. Op. cit., p. 237.

31. Ibid.

32. Id., p. 137

33. Id., p. 86. 
Mesmo quando encontramos no romance trechos que nos lembram as paradas descritivas observadas por Ligia Chiappini em obras regionalistas, percebemos neles a fratura justamente porque não se distanciam das personagens. Veja-se um desses momentos:

Os tucunazeiros carregados guardavam o caminho para o igarapé. Lá dentro os cipoais, o escondido, os folhedos macios cheirando a lacre e a baunilha, os puruizeiros davam seus frutos silvestres parecidos com uvas. Chupavam puruí juntos. Agora havia dois puruís bem pretos, desfazendo-se de maduros, naqueles olhos. Maré enchendo, a ansiedade subindo. Exibia um porte de filha taxaua, alta, carnuda, peito cheio. ${ }^{34}$

O excerto revela o pensamento de Missunga ao "tomar café bebendo também os olhos de Guíta", anunciado em parágrafo anterior. Os grifos ajudam a ilustrar a metaforização por que passa o pensamento do rapaz, que traz à tona não somente a semelhança dos olhos de Guíta com o puruí, mas também um tempo distante em que os dois eram companheiros. Logo, a descrição de um narrador preocupado em reproduzir belamente a paisagem cede lugar a uma personagem que seleciona dessa paisagem os elementos analógicos e os combina em seus pensamentos conforme suas necessidades e possibilidades estéticas.

Já em Chove nos campos de Cachoeira, a despeito de toda a chuva e de toda a água, o tom regional é sufragado pelo drama interno das personagens de Eutanázio e Alfredo, ambos de mentalidade essencialmente urbana. Salta do texto a atmosfera densa, carregada pelo lado fortemente gauche de Eutanázio e - por que não? - de Alfredo. As náuseas do primeiro, em tensão contínua consigo mesmo, e o sofrimento do segundo, em tensão contínua porque quer efetivar o sonho de homem da urbe (no caso, estudar em Belém), prendem o leitor de tal modo que lhe ofuscam o olhar sobre o local. Afinal, aqueles heróis - gauches, pobres-diabos fracassados ou impotentes, fadados ao fracasso - nos dão os caminhos da leitura da obra: do existencialismo ao realismo crítico, prova de que Dalcídio Jurandir não amarrou seu texto nas estreitezas do naturalismo que satisfez muitos autores da época e que serviu a muitos críticos para assumir atitude de combate contra eles, conforme observa Luís Bueno ${ }^{35}$ a respeito de Flora Süssekind.

\footnotetext{
34. Id., p. 73 (grifo nosso).

35. Op. cit., p. 17 .
} 
Considerando, pois, os elementos de composição desses primeiros romances de Dalcídio Jurandir: a linguagem, o retrato do herói e as possibilidades de leitura desse herói, bem como o distanciamento do naturalismo, cremos que temos dados suficientes para alinhá-lo entre os bons romancistas de 30, complementando o quadro daqueles mais conhecidos. Esse enquadramento da obra de Dalcídio Jurandir ao lado de reconhecidos autores de 30 não se dá como provocação, tampouco como bairrismo, mas como releitura da década e da continuação de sua estética para a próxima, a de 40, e como forma de demonstrar que ao lado de autores canonizados caminham muitos outros que merecem ser relidos.

Marlí Tereza Furtado é professora no programa de pós-graduação em letras da Universidade Federal do Pará. 